\title{
Countertransference and Inpatient Psychiatry: Theoretical and Clinical Aspects
}

\author{
Edward Kim, MD \\ Jefferson Medical College, Philadelphia PA
}

Follow this and additional works at: https://jdc.jefferson.edu/jeffjpsychiatry

Part of the Psychiatry Commons

Let us know how access to this document benefits you

\section{Recommended Citation}

Kim, MD, Edward (1988) "Countertransference and Inpatient Psychiatry: Theoretical and Clinical Aspects," Jefferson Journal of Psychiatry. Vol. 6 : Iss. 2 , Article 17.

DOI: https://doi.org/10.29046/JJP.006.2.010

Available at: https://jdc.jefferson.edu/jeffjpsychiatry/vol6/iss2/17

This Article is brought to you for free and open access by the Jefferson Digital Commons. The Jefferson Digital Commons is a service of Thomas Jefferson University's Center for Teaching and Learning (CTL). The Commons is a showcase for Jefferson books and journals, peer-reviewed scholarly publications, unique historical collections from the University archives, and teaching tools. The Jefferson Digital Commons allows researchers and interested readers anywhere in the world to learn about and keep up to date with Jefferson scholarship. This article has been accepted for inclusion in Jefferson Journal of Psychiatry by an authorized administrator of the Jefferson Digital Commons. For more information, please contact: JeffersonDigitalCommons@jefferson.edu. 


\title{
Countertransference and Inpatient Psychiatry: Theoretical and Clinical Aspects
}

\author{
Edward Kim, M.D.
}

\section{INTRODUCTION}

Few aspects of psychiatric training are more troubling to beginning residents than the emerging awareness of their own countertransferences. This is often viewed with a mixture of disgust and embarassment as a sign of incompetence and lack of professionalism. Conflicting views on the origins of, and appropriate responses to countertransference further add to the difficulty and anxiety of psychiatric training. The frustration and sense of helplessness which often accompany these feelings can lead to disillusionment and various degrees of acting out which ultimately compromise patient care and resident education. Ironically, the feeling of being overwhelmed by countertransference can often occur several months into a psychiatric residency. Once beginning residents have acquired the basic clinical skills needed for acute diagnosis and treatment, subtler issues in patient management arise. The greater degree of psychiatric patient contact and greater difficulty in maintaining professional distance through procedures and lab studies makes this inevitable. It is often not until the outpatient years when residents begin to treat "higher functioning" patients that psychodynamic education is deemed clinically useful. Countertransference, like other psychodynamic topics, may be viewed as "irrelevant" to inpatient psychiatry, which emphasizes biological and behavioral interventions. At all levels of training, however, acquiring a systematic understanding of countertransference may be one of the most anxiolytic and educationally useful advances a resident can make.

\section{SPECIAL CHALLENGES OF INPATIENT PSYCHIATRY}

Patients are hospitalized for various reasons, but in general tend to be more severely regressed and disabled from their psychopathology. Short term acute care psychiatric units provide such patients with needed validation, support, containment, involvement, and structure (1). At times staff must provide such auxiliary ego functions as reality testing, impulse control, judgment, and self-object differentiation $(2,3)$. In short, the inpatient unit provides external substitutes or support for the intrapsychic structures which may be deficient or temporarily overwhelmed in patients. Kernberg (4) believes that patients using primitive borderline defenses communicate more of their unconscious issues nonverbally than do less regressed patients. In an inpatient unit, a patient's object relations are displayed through his or her interactions with other patients 
and staff members, providing the treatment team with important clinical data (2). On the other hand, because acting out is more likely in regressed patients, strong countertransference reactions can be elicited. The challenge of inpatient psychiatry is the use of these reactions for diagnostic and therapeutic purposes.

Units organized along the therapeutic community model confront a junior resident with multiple administrative challenges for which medical school offers little or no preparation. These responsibilities can interfere with the necessary recognition and processing of his or her countertransference. The usual workload of treatment team meetings, family meetings and therapy groups can be complicated by the special needs of handicapped or medically ill patients who require frequent lab studies and subspecialty consultations. In such cases, the very milieu which is designed to assist the resident in structuring patient care can become a burden. Night call duties divert still more time and energy from working through countertransference. While daily inpatient therapy sessions are usually briefer than their outpatient counterparts, they nevertheless tax the resident's adaptive capabilities in an additive fashion. Countertransference difficulties can rapidly escalate to unmanageable proportions given the acuity of patients, frequency of contact, and lack of time for therapeutic reflection. As a result, these feelings may be overlooked or acted upon, causing resident frustration and treatment difficulties.

\section{TWO VIEWS OF COUNTERTRANSFERENCE}

Freud initially described countertransference as the therapist's unconscious response to the patient's transference, stressing the analyst's need to overcome this obstacle to successful treatment (5). Later, he seemed to view countertransference with some ambivalence. In the same paper in which he encouraged analysts to adopt the aloof, dispassionate attitude of a surgeon, he also describes the analyst's unconscious mind as a "receptive organ" which receives and reconstructs the encoded data of the "transmitting unconscious" of the patient (6). This apparent contradiction seems to stem from ambiguity and conflict surrounding the very definition of countertransference.

The "classical" definition limits countertransference to the therapist's own neurotic conflicts. Cohen (7) defines it as any anxiety in the therapist which interferes with communication in the therapeutic situation. Gitelson (8) divides countertransference into two categories. The "total" reactions to the patient result from "surviving neurotic transference potential." These are felt to be more problematic since they will consistently interfere with the therapy through neurotic distortions on the part of the therapist. The "partial" reactions occur episodically whenever the therapy touches on unresolved conflicts in the therapist; the therapist's overall perception of the patient is relatively undistorted. In both Cohen's and Gitelson's models, countertransference is a neurotic symptom in the therapist which interferes with treatment. Freud's own countertransference difficulties in the treatment of "Dora" (9) has been the subject of 
close scrutiny and conforms to this model $(10,11)$. The classical therapeutic ideal of analyst-as-mirror is threatened by countertransference, which mars the "objectivity" of the analytic situation.

This attitude dominated psychoanalytic thought until the mid-1940's when two major theoretical movements explored the interpersonal dimensions of psychoanalysis. Under the influence of Sullivan, Erikson, and others, the neo-Freudian psychoanalysts elaborated on social and cultural contributions to personality development. The British school of object relations under Melanie Klein stressed the importance of the individuals toward whom patients' drives are directed. The concept of analyst-as-mirror evolved into one which considered the analyst as a participant in a necessarily interactional relationship (11).

Kernberg (12) offers three main criticisms of the classical view of countertransference, namely (i) it fosters a phobic avoidance of the therapist's emotional reactions; (ii) it limits his or her understanding of the nonverbal dynamics of the therapeutic situation; and (iii) it deprives the therapist of a sensitive tool for understanding severely chaotic patients such as borderlines and psychotics. $\mathrm{He}$ goes on to advocate a more "totalistic" conceptualization of countertransference which considers the therapist's response to the patient's reality (true experience), as well as his or her fantasy (transference). Kernberg believes that along the continuum from neurosis to psychosis, the patient's transference contributes more to countertransference than the therapists's own past experience. Thus, he states:

Given reasonably well-adjusted therapists, all hypothetically dealing with the same severely regressed and disorganized patient, their countertransference reactions will be somewhat similar, reflecting the patient's problems much more than any specific problem of the therapist's past. (p.43).

Winnicott (13) proposes the existence of an "objective" countertransference which he defines as "the analyst's love and hate in reaction to the actual personality and behavior of the patient, based on objective observation." In some cases, he claims, the patient actually needs to receive the objective hate he or she seeks through acting out as a precursor to receiving objective love. This expands the concept of empathy beyond the data-gathering receptiveness of the therapist to include his or her ability to intervene in a manner appropriate to the patient's current state (14).

Annie Reich (15) attempts to reconcile the conflict between the classical and totalistic definitions of countertransference by calling the former countertransference and the latter empathy. She stresses that empathy can lead to neurotic countertransference if the therapist's own conflicts are activated by empathic identification with the patient. A further differentiation that she makes between countertransference and empathy is that in the latter the therapist is able to move freely between empathic identification and an objective, theoretical understanding of the patient. 


\section{COUNTERTRANSFERENCE AND THE THERAPEUTIC PROCESS}

Severely regressed patients present special difficulties resulting from the therapeutic process itself as well as from their individual pathology. Empathy, a vital substrate in the therapeutic process, involves what Fliess (16) calls "trial identification" with the patient. The therapist's empathic response to the patient's transference takes place in four phases: (i) the therapist is the object of the patient's striving: (ii) he or she identifies with the patient; (iii) the therapist then experiences this affect first hand; (iv) he or she then projects the striving back onto the patient and is able to be detached from it. Greenson (17) describes empathy as the construction of "a special kind of internal object representative" which is neither merged with nor alien from the therapist's self-representation. Schafer (18) refers to this internal representation as "a substructure of the analyst's ego" which is consistently accessible to the therapist for trial identifications. Arlow $(19,20)$ describes empathy as "sharing the patient's unconscious fantasy." The therapist may experience a "signal affect" or fantasy which seems alien to his or her current state of mind. This alerts the therapist that the patient may also be experiencing this to some degree.

Empathic trial identification utilizes the rudimentary mechanisms of introjection and projection in order to establish this special internal representation of the patient within the therapist's ego (16). Kernberg (13) warns that at some point this process can reactivate the therapist's own early conflicts. This can result in anxiety over aggressive, primitive impulses, weakened ego boundaries with the patient, and the subsequent urge to control the patient who represents the source and/or object of these impulses. The therapists's mature adaptive and cognitive structures provide the stability and support necessary to proceed with the therapy despite this partial, transient regression. Moreover, the therapist's reactions are usually of less amplitude and shorter duration than the patient's as a result of his or her greater ability to work through the empathic regression (7). Because of this, he or she can make objective use of empathically acquired data to understand the inner life of the patient.

\section{PATIENT CONTRIBUTIONS TO COUNTERTRANSFERENCE}

Transference hate on the part of very regressed patients may play a large role in eliciting primitive countertransference. Such hate may derive from a fear or expectation of abandonment. Conflicts over intimacy can cause patients to see the therapist as both a source of nurturing comfort and punitive annihilation (21). Transference hate is a manifestation of the aggressive drive derivatives characteristic of borderline pathology (22). By itself, this hate is not nearly as problematic as the tendency of psychotic and borderline patients to unconsciously manipulate the therapeutic relationship. This provokes the expected countertransference responses and thus validates transference distortions $(7,21)$. Devaluation or misinterpretation of the therapist, splitting, and acting 
out are some ways in which this is accomplished. No therapist, however competent, can tolerate such chaotic, rapidly shifting attitudes and behavior indefinitely; residents should therefore anticipate these primitive countertransference impulses $(14,21)$. Through projective identification, a patient may project aggression onto the therapist who then experiences this hate as his or her own (4). If the therapist expresses some of this aggression, the patient's distortions are confirmed and the therapist may become even angrier at the realization that he or she has been so effectively manipulated.

\section{CONSEQUENCES OF COUNTERTRANSFERENCE}

Both empathic identification and transference provocation challenge the therapist's identity, equilibrium, and objectivity. The inevitable activation of countertransference hate toward chaotic, severely regressed patients can be experienced as aversion, the desire to reject or escape from the patient, or malice, the desire to punish or dominate the patient. Other signs include somatic symptoms such as muscular tension and sexual or autonomic arousal (21). Beginning residents may become frightened, understandably, when confronted with their own reactions to patients' intense and chaotic transference. The narcissistic desire to heal all, know all, and love all, can lead residents to use various defenses to ward off the awareness of these primitive feelings. Repressed hatred may result in inattentiveness, boredom, or vague anxiety with the patient. Internalized hatred can produce despair, depression, and a masochistic acceptance of the patient's insults. Through reaction formation the therapist may become over-involved or indulgent with the patient, entertaining magical fantasies of rescue or cure. As the therapist's reality testing weakens, he or she may project this hate, resulting in an unreasoning fear that the patient will commit suicide, or in paranoid fantasies involving fears of assault or humiliation by the patient. Outright denial of countertransference hate results in the therapist labelling the patient "hopeless," a "bad borderline," or a "sociopath" $(4,21,23)$. Further regression in the therapist may result in a fear of therapy sessions as the patient comes to represent a punitive object in the therapist's past (24).

\section{CASE EXAMPLES}

The following case examples of countertransference reactions demonstrate how they were managed to enhance the treatment of severely regressed inpatients.

\section{Case 1: Confronting Provocative Resistance}

A manic patient consented to "any medicine" the resident wished to use, but immediately responded to the resident's suggestions with hostility, challeng- 
ing the resident to place him in restraints and administer intragluteal injections of medication. Aware of his own countertransference aggression toward the patient, this resident asked the patient why he was trying to make him angry. The patient responded by slumping sadly in his chair and commenting on how "screwed up" his life had become because of his illness (he had been evicted from his apartment because of violence leading to his involuntary commitment). He also went on to discuss how he felt that the physicians on the unit "defeated" him with their "mental strength." This man may have been struggling with conflicts surrounding submissive desires for intimacy and nurturing and a psychotic fear of homosexual assault. By casting the resident in the role of aggressor, the patient could passively receive some of this "strength" without consciously submitting to an invasion. While the patient remained very ambivalent and chaotic in his relationship with the resident, the consistent identification of this defense defused several potentially volatile situations.

\section{Case 2: Reaction Formation by Staff}

A patient with a history of threatening and self-destructive behavior became irate over a behavioral contract presented to him after readmission to a voluntary unit, and threatened to sign out of the hospital. He was hostile, paranoid, at times suicidal. The resident and nursing staff were anxious to prevent the patient from signing out and called a conference with the patient. The attending, sensing the other staff's over-involvement with the patient's decision, told the patient that he should decide for himself whether or not he wished to remain in the hospital under the stipulated contract. The patient responded by writing a nearly identical and more comprehensive contract of his own which he fulfilled for the remainder of his hospitalization.

The staff members harbored residual countertransference hate for the patient from a previous admission during which he was verbally abusive and physically threatening. Their fear and anger upon his readmission led them to become over-controlling and enmeshed with the patient, who responded with the paranoid expectation of sadistic punishment. Given a more appropriate level of autonomy, the patient was able to structure his behavior and express aggression in a more sublimated way, resulting in a stronger therapeutic alliance during his brief hospitalization. The staff had committed an empathic failure by attempting to give the patient more direction and structure than he needed.

\section{Case 3: Projective Identification Onto the Therapist}

A borderline patient became actively suicidal regarding her intended separation and divorce from her alcoholic husband. During her hospitalization she acted out her ambivalence by changing her plans to apply for separate housing several times. She also asked her husband to come to the unit on several occasions to bring small "necessary" items from home. The resident treating 
her began to feel confused about how to manage this patient and hopeless about the likelihood of the separation lasting more than a few weeks. Moreover, he entertained fantasies that the patient would never be discharged because of her blurring and unconscious sabotage of discharge planning.

It was pointed out in supervision that the resident was experiencing the patient's own ambivalence about these plans. He was then able to empathically confront her obfuscation in the context of her feeling overwhelmed by very difficult and affect-laden decisions. Moreover, he was able to avoid supporting either side of the patient's ambivalence when she decided to return to her husband, essentially nullifying the manifest "purpose" for her hospitalization.

\section{DISCUSSION}

Early recognition of countertransference toward hospitalized patients is more vital yet more difficult due to the demands of inpatient psychiatry. Kernberg (4) states that with patients using primitive defenses, countertransference feelings are largely worked through outside of therapeutic sessions. The hectic schedule of inpatient units leaves little time for this to occur with any consistency. Managing countertransference is a constant challenge, and residents will inevitably fail at times to recognize and react appropriately to these feelings. Some basic guidelines can help when patients stir up strong reactions:

\section{Countertransference Is Inevitable}

No one is immune to the activation of previously resolved or unresolved conflicts in clinical practice. While neurotic responses to patient material are undesirable and countertherapeutic if acted upon, this is a necessary risk, if one wishes to develop therapeutic empathy. As residents gain more experience, they will hopefully be able to utilize their responses in a manner less dominated by repression and other defenses. However, as Kernberg (13) points out, a phobic avoidance of this phenomenon will only hinder the development of empathy.

\section{The Therapist Isn't Always Wrong}

Even a neurotic countertransference reaction is not always the sole product of the therapist. Patients who have regressed to preverbal modes of empathy and communication may be extremely perceptive about the vulnerabilities of their therapists (25). The ways in which patients exploit these vulnerabilities can give significant information about their own object relations regardless of whether or not the therapist's feelings are "objective." In many respects, the very irrationality of some countertransference feelings serves as a marker inviting further reflection through supervision, personal therapy, or self-analysis. A resident who understands the sources of his or her countertransferences is in a position to better understand the patients who activate these reactions. 


\section{The Patient Isn't Always Wrong}

No matter how obvious the patient's part in the development of countertransference, it is only one part of an interpersonal equation which includes the therapist. An approach which ignores this is bound to result in frequent empathic failures at best, and frequent therapist acting out at worst.

\section{Fantasies and Associations Can Be Helpful}

The unconscious material communicated nonverbally by regressed patients often comes to the therapist's attention in forms which may seem to be intrusive or inappropriate. This "shared fantasy" can reveal much about the patient. If the above guidelines can be followed, the liberal use of the therapist's unconscious resources should be encouraged.

\section{CONCLUSIONS}

The issue of countertransference will always be affect-laden, particularly to beginning residents. The unique nature of psychiatry is such that the boundaries between our instruments and our personalities can become very ambiguous. Clinical competence and personal worth may at times become too intimately connected or confused, more so than in other specialties. If we accept countertransference as an inevitable conscious and unconscious reaction to the patient, we can then look to it as a useful diagnostic instrument rather than merely a sign of failure or neurosis (though that cannot always be discounted). For the psychiatric resident treating severely regressed inpatients, early recognition of countertransference, avoidance of acting out, and appropriate utilization of this insight can greatly relieve the strain and drain of the inpatient years.

\section{REFERENCES}

1. Gunderson JG: Defining the therapeutic processes in psychiatric milieus. Psychiatry 37:137-146, 1978

2. Gabbard GO: A contemporary perspective on psychoanalytically informed hospital treatment. Hosp Comm Psychiatry 39:1291-1295, 1988

3. Oldham JM, Russakoff LM: Dynamic Therapy in Brief Hospitalization. London, Jason Aronson, Inc, 1987

4. Kernberg O: Projective identification: developmental and clinical aspects. J Am Psychoanal Assoc 35:795-819, 1987

5. Freud S: The future prospects of psycho-analytic therapy (1910). Standard Edition, 11:139-151. London, Hogarth Press, 1957

6. Freud S: Recommendations for physicians on the psycho-analytic method of treatment (1912). Standard Edition, 12:109-120, London, Hogarth Press, 1957

7. Cohen MB: Countertransference and anxiety. Psychiatry 15:231-243, 1952

8. Gitelson M: The emotional position of the analyst in the psycho-analytic situation. Int J Psychoanal 33:1-10, 1952 
9. Freud S: Fragment of the analysis of a case of hysteria (1905). Standard Edition, 7:3-121, London, Hogarth Press, 1957

10. Glenn J: Freud, Dora, and the maid: a study of countertransference. J Am Psychoanal Assoc 34:591-606, 1986

11. Jennings JL: The revival of "Dora": advances in psychoanalytic theory and technique. J Am Psychoanal Assoc 34:607-635, 1986

12. Kernberg O: Notes on countertransference. J Am Psychoanal Assoc 13:38-56, 1965

13. Winnicott DW: Hate in the counter-transference. Internat J Psychoanal 30(pt.2):6974,1949

14. Levy ST: Empathy and psychoanalytic technique. J Am Psychoanal Assoc 33:353373,1985

15. Reich A: Further remarks on counter-transference. Internat J Psychoanal 41:389395,1960

16. Fliess R: The metapsychology of the analyst. Psychoanal Quart 11:211-227, 1942

17. Greenson RR: Empathy and its vicissitudes. Internat J Psychoanal 41:418-424, 1960

18. Schafer R: Generative empathy in the treatment situation. Psychoanal Quart 28:342-373, 1959

19. Beres D, Arlow JA: Fantasy and identification in empathy. Psychoanal Quart 43:26-50, 1974

20. Arlow JA: Some technical problems of countertransference. Psychoanal Quart $54: 164-174,1985$

21. Maltsberger JT, Buie DH: Countertransference hate in the treatment of suicidal patients. Arch Gen Psychiatry 30:625-633

22. Kernberg O: Borderline personality organization. J Am Psychoanal Assoc 15:641685,1967

23. Reiser DE, Levenson $\mathrm{H}$ : Abuses of the borderline diagnosis: a clinical problem with teaching opportunities. Am J Psychiatry 141:1528-1532, 1984

24. Benedek T: Dynamics of the countertransference. Bull Menninger Clin 17:201-208, 1963

25. Krohn A: Borderline "empathy" and differentiation of object representations: a contribution to the psychology of object relations. Int J Psychoanal Psychother $3: 142-165,1974$ 